Erik Jan van Lieshout

Rien de Vos

Jan M. Binnekade

Rob de Haan

Marcus J. Schultz

Margreeth B. Vroom

\section{Decision making in interhospital transport of critically ill patients: national questionnaire survey among critical care physicians}

Received: 15 July 2007

Accepted: 17 January 2008

Published online: 19 February 2008

(C) The Author(s) 2008

E. J. van Lieshout ( J J M. Binnekade . M. J. Schultz · M. B. Vroom

University of Amsterdam, Department of Intensive Care Medicine, Academic Medical Center,

Meibergdreef 9, 1105 AZ Amsterdam,

Netherlands

e-mail: E.J.vanLieshout@amc.nl

E. J. van Lieshout

University of Amsterdam, Mobile Intensive

Care Unit, Academic Medical Center,

Meibergdreef 9, 1105 AZ Amsterdam,

Netherlands

R. de Vos $\cdot$ R. de Haan

University of Amsterdam, Clinical

Epidemiology, Biostatistics and

Bioinformatics, Academic Medical Center,

Meibergdreef 9, 1105 AZ Amsterdam,

Netherlands

\section{J. Schultz}

University of Amsterdam, Laboratory of Experimental Intensive Care and

Anesthesiology, Academic Medical Center,

Meibergdreef 9, 1105 AZ Amsterdam,

Netherlands
Abstract Objective: This study assessed the relative importance of clinical and transport-related factors in physicians' decision-making regarding the interhospital transport of critically ill patients. Methods: The medical heads of all 95 ICUs in The Netherlands were surveyed with a questionnaire using 16 case vignettes to evaluate preferences for transportability; 78 physicians $(82 \%)$ participated. The vignettes varied in eight factors with regard to severity of illness and transport conditions. Their relative weights were calculated for each level of the factors by conjoint analysis and expressed in $\beta$. The reference value $(\beta=0)$ was defined as the optimal conditions for critical care transport; a negative $\beta$ indicated preference against transportability. Results: The type of escorting personnel (paramedic only: $\beta=-3.1$ ) and transport facilities (standard ambulance $\beta=-1.21$ ) had the greatest negative effect on preference for transportability. Determinants reflecting severity of illness were of relative minor importance (dose of noradrenaline $\beta=-0.6$, arterial oxygenation $\beta=-0.8$, level of peep $\beta=-0.6$ ). Age, cardiac arrhythmia, and the indication for transport had no significant effect. Conclusions: Escorting personnel and transport facilities in interhospital transport were considered as most important by intensive care physicians in determining transportability. When these factors are optimal, even severely critically ill patients are considered able to undergo transport. Further clinical research should tailor transport conditions to optimize the use of expensive resources in those inevitable road trips.

Keywords Transportation of patients - Patient transfer - Interhospital transfer - Critical care . Questionnaire $\cdot$ Conjoint analysis

\section{Introduction}

Interhospital transport of critically ill patient may be indicated if additional care, whether technical, cognitive, or procedural, is not available at the existing location [1]. Regionalization of intensive care medicine in centers with high patient volumes appears to improve outcome of patients and therefore may further increase the need for these transports [2-4]. The risks associated with interhospital transport should be weighted against its potential benefit for each individual critically ill patient [5-7]. The use of specialized teams and appropriate equipment might reduce these risks $[8,9]$. Although guidelines have been developed to increase the safety of interhospital transport of critically ill patients, clinical evidence is lacking on factors determining the transportability of these 
patients $[1,4]$. Decision-making in interhospital transport involves appraisal of several determinants including patient characteristics, indication for transport, level of escort, and transport facilities. The process of appraisal of these variables, however, has never been studied [10].

The aim of the present study was to assess the relative importance of clinical and transport-related determinants influencing physicians' decision-making in interhospital transport of critically ill patients.

\section{Methods}

We sent a national questionnaire survey with paper case descriptions, so-called clinical vignettes, to the medical heads (intensivist or supervising consultant) of all 95 intensive care units (ICUs) in The Netherlands. Neonatal and pediatric ICUs were excluded. Questionnaires were anonymous but coded, and therefore so nonresponders could be followed up with a postal reminder 2 months later. A prepaid envelope was included for its return, and a web-based version was available for digital responses. Of the 95 questionnaires $78(82 \%)$ were returned and all were suitable for analysis. Respondents' mean age was $45 \pm 6.6$ years (Table 1$)$. Most $(n=66,86 \%)$ were intensivists with either anesthesiology or internal medicine as medical specialty. The median number of interhospital transport leaving their ICU was one per month, with a considerable range $(0.01-12)$.

The interhospital critical care transport system in The Netherlands is diverse. The majority of the transports are by ground (standard) ambulances escorted by an advanced life-support paramedic and occasionally complemented by the sending physician. Only a few regions use a dedicated, fully equipped mobile ICU with an escorting team of intensive care (IC) physician and IC nurse.

Table 1 Characteristics of the 78 responding intensive care physicians and their hospitals

\begin{tabular}{lc}
\hline Mean age (years) & $45( \pm 6.6)$ \\
\hline Medical speciality (\%) & \\
Intensive care medicine & $66(86 \%)$ \\
Anesthesiology & $37(48 \%)$ \\
Internal medicine & $34(44 \%)$ \\
Surgery & $1(1 \%)$ \\
Other & $5(7 \%)$ \\
Type of hospital & $13(17 \%)$ \\
Academic medical center & $34(44 \%)$ \\
Teaching hospital, nonacademic & $30(38 \%)$ \\
Regional public hospital & $8(2-42)$ \\
Number of beds in ICU, median (range) & $1(0.01-12)$ \\
Number of interhospital transport & \\
per month median (range) & \\
\hline
\end{tabular}

${ }^{\mathrm{a}}$ Multiple specialities per physician possible
The questionnaire

The questionnaire consisted of two parts: (a) characteristics of the respondent and its ICU including frequency of interhospital ICU transport from their hospital; (b) 16 clinical vignettes.

\section{Clinical vignettes}

The 16 clinical vignettes are showed in Table 2. We identified eight potential determinants in decision making of IC transport which are known from clinical studies and critical care transport experience from the authors $[1,6-9,11,12]$. The determinants were incorporated in the clinical vignettes: (a) age (30 vs. 60 vs. 80 years); (b) arterial oxygenation pressure (7.5 vs. $16.5 \mathrm{kPa})$; (c) level of positive expiratory pressure (PEEP) (8 vs. $18 \mathrm{cmH}_{2} \mathrm{O}$ ); (d) dose of noradrenaline infusion ( $0.12 \mathrm{vs}$. $0.60 \mu \mathrm{g} / \mathrm{kg}$ per minute); (e) arrhythmia (self-terminating ventricular tachycardia $<24 \mathrm{~h}$ vs. no arrhythmia within $6 \mathrm{~h}$ ); (f) transport facility (fully equipped mobile ICU, i.e., IC ventilator, IC monitor including invasive blood pressure monitoring and capnography, sufficient number of syringe pumps) vs. standard ambulance (i.e., transport ventilator without IC performance, no invasive and capnography monitoring); (g) escorting personnel paramedic (advanced life support paramedic characterized by, e.g., protocolized advanced life support with medication, cardiopulmonary resuscitation intubation) vs. IC physician and paramedic vs. IC nurse and paramedic vs. team of IC physician and IC nurse and paramedic; (h) indication for transport (shortage of ICU beds in referring hospital vs. essential intervention not available in referring hospital).

As 768 case descriptions were needed to present all possible combinations of the eight determinants and their levels, the number of representative clinical vignettes were reduced to 16 using an orthogonal main-effects design [13]. This approach permits the statistical testing by conjoint analysis of a suitable fraction of all possible combinations of the factors (determinants) and their levels.

Respondents were asked to rate the degree of transportability, defined as their personal clinical decision, whether they would let this patient be transported, for each of the 16 critically ill patients described in clinical vignettes. A seven point Likert scale was used ranging from 1 ("entirely not transportable") to 7 ("definitely transportable"). It was emphasized that no true or false answers were sought but their clinical judgment.

\section{Statistical analysis}

The means and standard deviations for continuous variables and distributions for frequency of categorical variables were summarized using descriptive statistics. 
Table 2 The 16 case vignettes. Basic structure of each case vignette: patient admitted to ICU after initial presentation in the emergency department with severe sepsis (probably pneumococcal), Acute Physiology and Chronic Health Evaluation II of 18, mean

\begin{tabular}{|c|c|c|c|c|c|c|c|c|}
\hline & \multicolumn{5}{|c|}{ Patients characteristics } & \multicolumn{3}{|c|}{ Transport conditions } \\
\hline & $\begin{array}{l}\text { Age } \\
\text { (years) }\end{array}$ & $\begin{array}{l}\mathrm{paO}_{2} \\
(\mathrm{kPa})\end{array}$ & $\begin{array}{l}\text { PEEP } \\
\left(\mathrm{cmH}_{2} \mathrm{O}\right)\end{array}$ & $\begin{array}{l}\text { Noradrenaline } \\
(\mu \mathrm{g} / \mathrm{kg} \\
\text { per minute })\end{array}$ & Arrhythmia & Equipment & $\begin{array}{l}\text { Escorting } \\
\text { personnel }\end{array}$ & $\begin{array}{l}\text { Indication } \\
\text { for transport }\end{array}$ \\
\hline 1 & 30 & 16.5 & 18 & 0.12 & $\mathrm{VT}<24 \mathrm{~h}$ & MICU trolley & IC nurse & Lack of ICU beds \\
\hline 2 & 30 & 16.5 & 8 & 0.12 & None & Basic ambulance & $\begin{array}{l}\text { IC physician } \\
\text { and IC nurse }\end{array}$ & Intervention elsewhere \\
\hline 3 & 30 & 16.5 & 18 & 0.6 & None & Basic ambulance & Paramedic & Lack of ICU beds \\
\hline 4 & 30 & 7.5 & 8 & 0.6 & None & Basic ambulance & IC physician & Lack of ICU beds \\
\hline 5 & 30 & 7.5 & 8 & 0.12 & $\mathrm{VT}<24 \mathrm{~h}$ & MICU trolley & $\begin{array}{l}\text { IC physician } \\
\text { and IC nurse }\end{array}$ & Lack of ICU beds \\
\hline 6 & 80 & 7.5 & 8 & 0.6 & $\mathrm{VT}<24 \mathrm{~h}$ & Basic ambulance & IC nurse & Intervention elsewhere \\
\hline 7 & 80 & 16.5 & 8 & 0.12 & $\mathrm{VT}<24 \mathrm{~h}$ & Basic ambulance & Paramedic & Lack of ICU beds \\
\hline 8 & 60 & 7.5 & 8 & 0.12 & none & MICU trolley & Paramedic & Intervention elsewhere \\
\hline 9 & 30 & 7.5 & 18 & 0.12 & none & Basic ambulance & IC nurse & Intervention elsewhere \\
\hline 10 & 30 & 7.5 & 18 & 0.60 & $\mathrm{VT}<24 \mathrm{~h}$ & MICU trolley & Paramedic & Intervention elsewhere \\
\hline 11 & 30 & 16.5 & 8 & 0.60 & $\mathrm{VT}<24 \mathrm{~h}$ & MICU trolley & IC physician & Intervention elsewhere \\
\hline 12 & 60 & 16.5 & 18 & 0.60 & $\mathrm{VT}<24 \mathrm{~h}$ & Basic ambulance & $\begin{array}{l}\text { IC physician } \\
\text { and IC nurse }\end{array}$ & Intervention elsewhere \\
\hline 13 & 80 & 16.5 & 18 & 0.12 & none & MICU trolley & IC physician & Intervention elsewhere \\
\hline 14 & 60 & 7.5 & 18 & 0.12 & $\mathrm{VT}<24 \mathrm{~h}$ & Basic ambulance & IC physician & Lack of ICU beds \\
\hline 15 & 60 & 16.5 & 8 & 0.60 & none & MICU trolley & IC nurse & Lack of ICU beds \\
\hline 16 & 80 & 7.5 & 18 & 0.60 & none & MICU trolley & $\begin{array}{l}\text { IC physician } \\
\text { and IC nurse }\end{array}$ & Lack of ICU beds \\
\hline
\end{tabular}

arterial pressure of $70 \mathrm{mmHg}$ after adequate fluid-resuscitation, endotracheally intubated and mechanically ventilated with $50 \%$ $\mathrm{FIO}_{2}$ and after $6 \mathrm{~h}$ in the ICU need for interhospital transport [VT, ventricular tachycardia (self terminating); $M I C U$, mobile ICU]
Conjoint analysis was performed with transportability as dependent variable to calculate the relative weights for each level of the determinants [13]. This results in a utility score for each determinant level expressed in $\beta$ with $95 \%$ confidence interval. These utility scores, estimated by least squares regression analogous to regression coefficients, provide a quantitative measure of the preference for each determinant level, with larger values corresponding to greater preference.

Considering the individual respondents as random effects took into account that the preference score originating from 16 repeated measurements. Determinants with a negative $\beta$ indicated preference against transportability. The reference value, by definition $\beta=0$, was defined as the optimal conditions for critical care transport (youngest age, highest $\mathrm{PaO}_{2}$, lowest dose of noradrenaline, no arrhythmia, fully equipped mobile ICU ambulance, escorting team of IC physician and IC nurse, intervention required not available in own facility). The conjoint analysis was repeated in relation to (a) type of hospital the respondents were working in regional hospital or teaching/university hospital, (b) speciality of the respondent, and (c) the method of data collection, either paper or online questionnaire.

\section{Results}

The impact of the determinants in the decision making on transportability is displayed in Fig. 1. Those with the

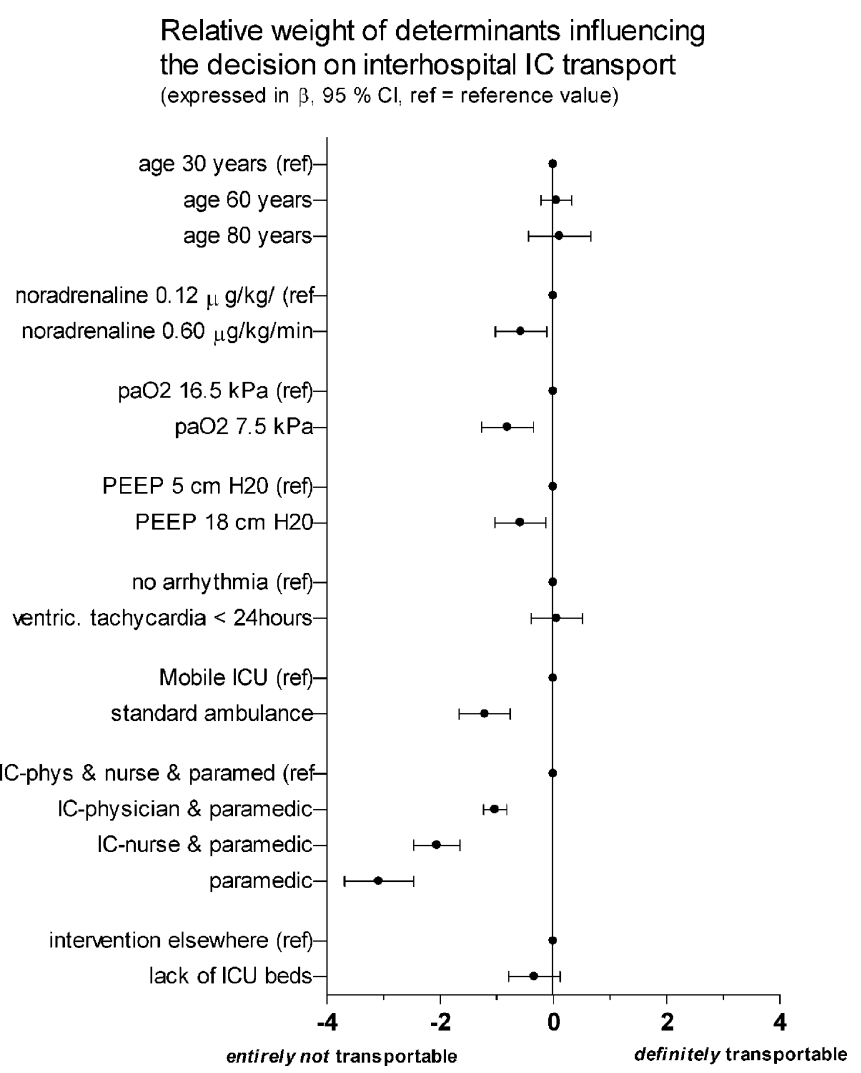

Fig. 1 Relative weight (expressed in $\beta, 95 \%$ confidence interval) of determinants influencing the decision on interhospital IC transport. ref, Reference value; PEEP, positive end-expiratory pressure; ventric, ventricular; $I C$, intensive care 
largest negative effects on preference for transportability were the type of escorting personnel [paramedic only: $\beta=-3.1(-3.7$ to -2.5$)$; IC nurse and paramedic: $\beta=-2.1$ $(-2.5$ to -1.7$)$; team of IC physician, nurse, and paramedic: $\beta=-1.0(-1.2$ to -0.8$)$; standard ambulance: $\beta=-1.21$ $(-1.7$ to -0.8$)$ ]. Determinants reflecting the critically ill patient's condition and intensity of treatment were scored to be of relative minor importance [dose of noradrenaline: $\beta=-0.6$ ( -1.0 to -0.1$)$; arterial oxygenation $\beta=-0.8(-1.3$ to -0.4$)$; level of PEEP $\beta=-0.6(-1.0$ to -0.1$)]$. Age [60 years: $\beta=0.1(-0.2$ to 0.3$)$; 80 years: $\beta=0.1[-0.4$ to $0.7)]$, cardiac arrhythmia $[\beta=0.1(-0.4$ to 0.5$)]$, and the indication for transport $(\beta=-0.3(-0.8$ to 0.1$)]$ had no significant effect on the preference for transportability (Fig. 1).

Repeated analyses did not demonstrate significant differences in relative weights of the determinants in relation to respondents' working location (regional hospital vs. large teaching hospital or academic medical center), type of medical speciality, or method of data collection (paper vs. online).

\section{Discussion}

Decision-making in interhospital transport involves appraisal of several determinants such as patient characteristics, indication for transport, level of escort, and transport facilities. The present study shows that the level of escorting personnel is an important determinant in decision-making in interhospital transport of a critically ill patient. Additionally, transport facilities are perceived as most important by the majority of medical heads of Dutch ICUs. Neither characteristics of the patient's condition nor the level of supportive care seems to be of significance in this process.

The large number of publications on interhospital transport reflects the interest in this complex part of IC medicine but are descriptive and mainly focuses on the technical and organizational aspects of transport $[1,9,12$, 14]. The use of specialized transport teams and appropriate equipment may result in a decrease in transport associated morbidity and mortality by creating an intensive care environment in a vehicle-ground ambulance or aircraft $[8$, 9, 15-17].

Despite the growth in interhospital transport due to regionalization of intensive care medicine the process by which IC physicians identify patients transportability is not well known $[3,10,18]$. Transportability as a result of a professional analysis of the balance between risks and potential benefits of an individual transport is hard to define. The accumulating literature on improved outcome associated with ICUs treating larger volumes of patients (e.g., with severe sepsis or mechanical ventilation) is not adequately accompanied by research on clinical parameters determining transportability in such conditions $[19,20]$. A study by Lee et al. [10] used a question- naire with clinical scenarios before and after a program, including a 15-min training in the use of interhospital transfer rules [10]. After the start of the program clinical staff were able to make appropriate decisions using these guidelines focusing on diagnosis and physiology. To our knowledge, however, no study has mimicked decision making in interhospital transport with appraisal of several realistic and detailed determinants as in daily clinical practice (i.e., as those in tested in this conjoint analysis) by experienced intensivists who endorse such transports.

Age is an important prognostic factor, for mortality rates are higher in elderly than in younger ICU patients [21]. This has not been studied in transported IC patients, but it is conceivable that intensivists would weigh this determinant in their transportability decision. The finding of the present study that age does not influence decision making for transportability is remarkable. The same holds true for the level of PEEP, which seems representative for severity of oxygenation and is known to be a critical factor in transport [11]. IC physicians, however, seem to consider factors associated with severity of illness (age, PEEP, noradrenaline dose, oxygenation) to be less important than to transport conditions. International guidelines underline the importance of these conditions, but clinical transport studies and recommendations are lacking to address the issue of transport-related morbidity and mortality of extreme critical ill patients despite optimal expertise and equipment [7-9, 17, 22].

One of the limitations of this study is the intrinsic shortcoming of the vignette method. Paper case descriptions, so-called clinical vignettes, have been recognized as a valid policy capturing tool to assess preferences in clinical practice $[18,23]$. However, it is impossible to overcome the sentinel effect in which the physicians know they are being evaluated. Due to this "Hawthorne effect" there may be a discrepancy between physicians' decisions in practice and their answers to vignettes with hypothetical patients. Another limitation is the choice of content of the vignettes with eight determinants of transportability. The content of vignettes survey is limited to a number of determinants with their corresponding levels as an intrinsic element of conjoint analysis to generate an optimal number of vignettes a respondent would still adequately evaluate [13]. The set of determinants used in this study is based only on literature and critical care transport experience and could therefore be biased $[1,6-9,11,12]$. Other, unknown factors could not be studied as critical in transport. Those factors would only be revealed in clinical transport studies documenting all clinical parameters and relate them with clinical outcome after transport. Finally, this national questionnaire survey is limited by the Dutch situation, where due to geography interhospital transport is carried out by ground ambulance without air medical transport. It is conceivable that the choice of vehicle is a crucial determinant in the decision making in combination with the interhospital distance [24]. 


\section{Conclusions}

This policy observing study indicates the importance of optimal escorting and transport facilities in interhospital transport as appreciated by IC physicians. These conditions are considered to be essential and enable even severe critically ill patients to be transported. Further clinical (transport) research should reveal which levels of expertise and transport facilities are indicated for which category of critically ill patients to tailor the use of expensive resources required for those inevitable road trips $[9,17]$.
Acknowledgements. E.J.v.L. designed the study, performed the measurements, assisted in the statistical analyses, and drafted the manuscript. R.d.V. designed the study, performed the statistical analysis, and participated in drafting the manuscript. J.M.B. performed the statistical analysis and participated in drafting the manuscript. R.d.H. participated in the statistical analysis and drafting the manuscript. M.J.S. and M.B.V. participated in the study design and drafting the manuscript. All authors read and approved the final manuscript. We thank all our colleagues intensive care physicians who returned our questionnaire.

Open Access. This article is distributed under the terms of the Creative Commons Attribution Noncommercial License which permits any noncommercial use, distribution, and reproduction in any medium, provided the original author(s) and source are credited.

\section{References}

1. Warren J, Fromm RE Jr, Orr RA, Rotello LC, Horst HM (2004) Guidelines for the inter- and intrahospital transport of critically ill patients. Crit Care Med 32:256-262

2. Pronovost PJ, Angus DC, Dorman T, Robinson KA, Dremsizov TT, Young TL (2002) Physician staffing patterns and clinical outcomes in critically ill patients: a systematic review. JAMA 288:2151-2162

3. Mackenzie PA, Smith EA, Wallace PG (1997) Transfer of adults between intensive care units in the United Kingdom: postal survey. BMJ 314:1455-1456

4. Fan E, Macdonald RD, Adhikari NK, Scales DC, Wax RS, Stewart TE, Ferguson ND (2005) Outcomes of interfacility critical care adult patient transport: a systematic review. Crit Care 10:R6

5. Duke GJ, Green JV (2001) Outcome of critically ill patients undergoing interhospital transfer. Med J Aust 174:122-125

6. Durairaj L, Will JG, Torner JC, Doebbeling BN (2003) Prognostic factors for mortality following interhospital transfers to the medical intensive care unit of a tertiary referral center. Crit Care Med 31:1981-1986

7. Flabouris A, Runciman WB, Levings B (2006) Incidents during out-of-hospital patient transportation. Anaesth Intensive Care 34:228-236

8. Bellingan $\mathrm{G}$, Olivier T, Batson $\mathrm{S}$, Webb A (2000) Comparison of a specialist retrieval team with current United Kingdom practice for the transport of critically ill patients. Intensive Care Med 26:740-744
9. Belway D, Henderson W, Keenan SP, Levy AR, Dodek PM (2006) Do specialist transport personnel improve hospital outcome in critically ill patients transferred to higher centers? A systematic review. J Crit Care 21:8-17

10. Lee A, Lum ME, Beehan SJ, Hillman KM (1996) Interhospital transfers: decision-making in critical care areas. Crit Care Med 24:618-622

11. Waydhas C, Schneck G, Duswald KH (1995) Deterioration of respiratory function after intra-hospital transport of critically ill surgical patients. Intensive Care Med 10:784-789

12. Marx G, Vangerow B, Hecker H, Leuwer M, Jankowski M, Piepenbrock S, Rueckoldt H (1998) Predictors of respiratory function deterioration after transfer of critically ill patients. Intensive Care Med 11:1157-1162

13. Aiman-Smith L, Scullen SE, Barr SH (2002) Conducting studies of decision making in organizational contexts: a tutorial for policy-capturing and other regression-based techniques. Org Res Methods 5:388-414

14. Beckmann U, Gillies DM, Berenholtz SM, Wu AW, Pronovost P (2004) Incidents relating to the intra-hospital transfer of critically ill patients. An analysis of the reports submitted to the Australian Incident Monitoring Study in Intensive Care. Intensive Care Med 30:1579-1585

15. Edge WE, Kanter RK, Weigle CG, Walsh RF (1994) Reduction of morbidity in interhospital transport by specialized pediatric staff. Crit Care Med 22:1186-1191

16. Beyer AJ III, Land G, Zaritsky A (1992) Nonphysician transport of intubated pediatric patients: a system evaluation. Crit Care Med 20:961-966
17. Gebremichael M, Borg U, Habashi NM, Cottingham C, Cunsolo L, McCunn M, Reynolds HN (2000) Interhospital transport of the extremely ill patient: the mobile intensive care unit. Crit Care Med 28:79-85

18. Escher M, Perneger TV, Chevrolet JC (2004) National questionnaire survey on what influences doctors' decisions about admission to intensive care. BMJ 329:425-429

19. Peelen L, de Keizer NF, Peek N, Scheffer GJ, van der Voort PH, de Jonge E (2007) The influence of volume and intensive care unit organization on hospital mortality in patients admitted with severe sepsis: a retrospective multicentre cohort study. Crit Care 11:R40

20. Kahn JM, Goss CH, Heagerty PJ, Kramer AA, O'Brien CR, Rubenfeld GD (2006) Hospital volume and the outcomes of mechanical ventilation. N Engl J Med 355:41-50

21. de Rooij SE, Abu-Hanna A, Levi M, de Jonge E (2005) Factors that predict outcome of intensive care treatment in very elderly patients: a review. Crit Care 9:R307-R314

22. Council of the Intensive Care Society UK (2002) Guidelines for the transport of the critically ill adult. London: Intensive Care Society

23. Peabody JW, Luck J, Glassman P, Dresselhaus TR, Lee M (2000) Comparison of vignettes, standardized patients, and chart abstraction: a prospective validation study of 3 methods for measuring quality. JAMA 283:1715-1722

24. Flabouris A, Seppelt I (2001) Optimal interhospital transport systems for the critically ill. In: Vincent JL (ed) Yearbook of intensive care and emergency medicine. Springer, Berlin Heidelberg New York, pp 647-660 